\title{
STUDI EKSPLORASI ANTHROPOMETRI SISWA SEKOLAH MENENGAH KEJURUAN TEKNIK KENDARAAN RINGAN DI KOTA BANDUNG
}

\author{
Zenal Mutakin ${ }^{1}$, Wowo S. Kuswana ${ }^{2}$, Ridwan A.M. Noor ${ }^{3}$ \\ Departemen Pendidikan Teknik Mesin \\ Universitas Pendidikan Indonesia \\ Jl. Dr. Setiabudhi No. 207 Bandung 40154 \\ zenalmutakin90@gmail.com
}

\begin{abstract}
ABSTRAK
Tujuan penelitian ini yaitu untuk mengeksplorasi kondisi ketubuhan (postur) calon mekanik otomotif di industri berdasarkan analisis faktor ergonomi melalui pengukuran anthropometri siswa. Penelitian ini merupakan penelitian eksplorasi pengukuran anthropometri dilakukan pada 72 siswa SMK di Kota Bandung. Pengolahan data berupa uji keseragaman data, uji kecukupan data dan indeks massa tubuh, kemudian di deskripsikan berupa rata-rata dan kriteria kecocokan. Hasil pengukuran anthropometri kondisi ketubuhan (postur tubuh) calon mekanik otomotif kendaraan ringan pada pemetaan tingkat keseragamannya relatif rendah. Perbedaan data yang tinggi dan rendah apabila dilihat secara keseluruhan dari rata-rata siswa mempunyai tinggi badan rata-rata $165,30 \mathrm{~cm}$ dan berat badan rata-rata $56,68 \mathrm{~kg}$. Postur tersebut menunjukkan bahwa calon mekanik otomotif kendaraaan ringan tersebut memenuhi syarat untuk menjadi mekanik otomotif di Indonesia
\end{abstract}

Kata kunci: ergonomi, anthropometri, kendaraan ringan, postur.

\section{PENDAHULUAN}

Lulusan Sekolah Menengah Kejuruan (SMK) yang berkompeten dan berkualitas dihasilkan dari sebuah lembaga pendidikan yang memberikan pengalaman belajar yang baik pada siswanya. Pengalaman belajar yang baik ditentukan oleh Kurikulum, sarana dan prasarana serta guru pengajar. Karakteristik pengajaran di lingkungan pendidikan kejuruan seperti setingkat SMK Teknik Otomotif khususnya pada kelompok mata pelajaran produktif, yakni belajar yang didominasi oleh gerak motorik sebagai manifest pengetahuan dan sikap. Hal tersebut, ditunjukkan melalui performa proses dan hasil belajar siswa yang bersifat membekali ketangkasan di kemudian hari.

Kemampuan kerja fisik adalah suatu kemampuan fungsional dari seseorang untuk melakukan aktivitas kerja yang melibatkan kekuatan. Kompleksitas sistem ketubuhan manusia, dapat berjalan karena ada sistem kendali sebagai komponen yang dapat mengatur berbagai variabel masukan dalam proses mencapai tujuan. Sistem kendali tersebut, berpangkal dari sistem saraf otak yang bekerja relatif cepat melalui hantaran impuls elektris sepanjang saraf (Kuswana, 2013). Pekerjaan pada pemeliharaan atau servis pada bidang otomotif kendaraan ringan ini terutama servis engine menuntut posisi badan dan gerakan

\footnotetext{
${ }^{1}$ Mahasiswa Departemen Pendidikan Teknik Mesin FPTK UPI

2 Dosen Departemen Pendidikan Teknik Mesin FPTK UPI

${ }^{3}$ Dosen Departemen Pendidikan Teknik Mesin FPTK UPI
} 
fisik yang sangat bervariasi. Posisi badan tersebut harus menyesuaikan dengan kondisi kendaraan yang sedang di perbaiki sehingga kadang-kadang melakukan pekerjaan dengan posisi yang tidak aman, tidak nyaman atau canggung. Kodisi kerja seperti ini akan memaksa pekerja selalu berada pada sikap dan posisi kerja yang aneh dan kadang juga harus berlangsung dalam jangka waktu yang lama (Kuswana, 2015). Kegiatan tersebut tentu saja akan mengakibatkan pekerja cepat lelah, membuat banyak kesalahan kerja dan menderita cacat tubuh.

Penyebab kecelakaan, yang menyatakan bahwa terjadinya cedera merupakan hasil dari faktor kerumitan urutan pekerjaan, yang berakhir menjadi kecelakaan itu sendiri. Kedua, menyajikan sebuah model yang dikenal sebagai teori domino karena hal ini menurut urutan kejadian. Model domino telah dicatat sebagai satu dimensi dari suatu peristiwa. Kecelakaan biasanya, multifaktor dan berkembang melalui urutan yang relatif panjang perubahan dan kesalahan. Hal ini telah menyebabkan beberapa prinsip sebab akibat. Model Domino mengemukakan yakni ada penyebab langsung dan penyebab dasar. Penyebab langsung terjadinya kecelakaan yang dapat diobservasi dan diidentifikasi yakni unsafe act (tindakan tidak aman) dan unsafe condition (kondisi tidak aman). Faktor penyebab dasar merupakan salah satu awal kecelakaan, meskipun telah diidentifikasi. Sering kali adanya kemungkinan atau satu hal yang tidak sesuai dengan sesuai dengan instrumen saat seleksi pekerja. Penyebab dasar dapat diklasifikasikan menjadi dua hal, yaitu: faktor pribadi dan faktor pekerjaan. Berdasarkan faktor pribadi pekerja salah satunya kemampuan fisik atau fisiologi tidak memenuhi prasyarat pekerja yang dietapkan oleh dokter ahli yang merekomendasikan kelayakan untuk melaksanakan tugas tertentu (Kroemer, 2010). Berdasarkan faktor pekerjaan salah satunya sistem pengendalian dan pengawasan lemah, sistem pengadaan alat, bahan dan mesin tidak sesuai dengan standar, sistem pengembangan SDM kurang memadai, dan kesejahteraan kurang sesuai dengan tuntutan pekerjaan (Knudson, 2007).

Pekerjaan yang sehat dan aman merupakan hak setiap orang sebagai mana yang tercantum dalam Undang-undang Republik Indonesia Nomor 36 Tahun 2009 tentang Kesehatan. Pasal 4 menyatakan setiap orang berhak atas kesehatan. Pasal 6 menyatakan setiap orang berhak mendapatkan lingkungan yang sehat bagi pencapaian derajat kesehatan. Sehat diri dan lingkungan untuk pencapaian derajat kesehatan yang tinggi, pekerja memerlukan informasi dan edukasi

Ergonomi berbicara mengenai desain sistem terutama sistem kerja agar sesuai dengan atribut atau karakteristik manusia (fit the job to the man). Secara umum terdapat tiga macam 
cedera tubuh, yaitu cumulative trauma disorder (trauma gangguan kumulatif), repetitive strain injury, musculoskeletal disorder (gangguan muskuloskeletal) (Kuswana, 2014). Pendekatan khusus yang ada dalam disiplin ergonomi ialah aplikasi yang sistemis dari segala informasi yang relevan yang berkaitan dengan karakteristik dan perilaku manusia di dalam perancangan peralatan, fasilitas dan lingkungan kerja yang dipakai.

Analisis dan penelitian ergonomi akan meliputi hal-hal yang berkaitan dengan anatomi (struktur), fisiologi (bekerjanya) dan antropometri (ukuran) tubuh manusia. Psikologi yang fisiologis mengenai berfungsinya otak dan sistem syaraf yang berperan dalam tingkah laku manusia. Kondisi-kondisi kerja yang dapat mencederai baik dalam waktu pendek maupun panjang ataupun membuat celaka manusia dan sebaliknya ialah kondisi-kondisi kerja yang dapat membuat nyaman kerja manusia (Wignjosoebroto, 2003).

Antropometri adalah studi yang berkaitan dengan pengukuran dimensi tubuh manusia. Bidang antropometri meliputi berbagai ukuran tubuh manusia seperti berat badan, posisi ketika berdiri, ketika merentangkan tangan, lingkar tubuh, panjang tungkai, dan sebagainya (Preedy, 2012). Data antropometri digunakan untuk berbagai keperluan, seperti perancangan stasiun kerja, fasilitas kerja, dan desain produk agar diperoleh ukuran-ukuran yang sesuai dan layak dengan dimensi anggota tubuh manusia yang akan menggunakannnya (Gupta dan Zakaria, 2014). Data antropometri jelas diperlukan agar rancangan suatu produk bisa sesuai dengan orang yang akan mengoperasikannya. Ukuran tubuh yang diperlukan pada hakikatnya tidak sulit diperoleh dari pengukuran secara individual. Seperti halnya yang dijumpai untuk produk yang dibuat berdasarkan pesanan (job order). Situasi menjadi berubah manakala lebih banyak lagi produk standar yang harus dibuat dan dioperasikan oleh banyak orang. Permasalahan yang timbul di sini adalah ukuran siapa yang nantinya akan dipilih sebagai acuan untuk mewakili populasi.

\section{METODE PENELITIAN}

Metode penelitian yang digunakan adalah desain studi cross sectional. Penelitian noneksperimental dimana variabel yang terjadi pada objek penelitian diukur dan dikumpulkan dalam waktu yang bersamaan. Pendekatan penelitian ini bersifat kuantitatif observasional. Hasil penelitian akan disajikan dalam bentuk deskriptif, yaitu untuk melihat antropometri siswa SMK teknik kendaraan ringan di kota Bandung. Lokasi penelitian dilakukan di SMKN 6 dan SMKN 8 Kota Bandung. Waktu penelitian dilaksanakan pada periode bulan Juni 2015. Data yang disajikan berupa tabel, serta gambar/grafik. 


\section{HASIL PENELTIAN}

Data anthropometri diambil dari Siswa SMKN 6 dan SMKN 8 Kota Bandung. Jenis data anthropometri yang diambil sesuai dengan data penelitian yang telah ditentukan. Hasil data penelitian di uji dengan pengujian keseragaman data, kecukupan data dan indeks massa tubuh. Uji kecukupan data berfungsi untuk mengetahui apakah data yang diperoleh sudah mencukupi untuk diolah atau belum. Sebelum dilakukan uji kecukupan data terlebih dahulu menentukan derajat kebebasan 0,06 yang menunjukkan penyimpangan maksimum hasil penelitian. Selain itu juga ditentukan tingkat kepercayaan $95 \%$ dengan $\mathrm{k}=2$ yang menunjukan besarnya keyakinan pengukuran akan ketelitian data anthropometri, artinya bahwa rata-rata data hasil pengukuran diperbolehkan menyimpang sebesar 5\% dari rata-rata sebenarnya.

Data hasil pengukuran antropometri, rata-rata hasil pengukuran anthropometri siswa SMK teknik kendaraan ringan menunjukan ideal menjadi calon teknisi otomotif. Namun, ada beberapa diantaranya yang melebihi atau di bawah ideal.

\section{PEMBAHASAN}

Rata-rata postur tubuh siswa calon mekanik otomotif yang mempunyai rata-rata tinggi badan tegak 165,30 cm dibanding dengan negara asia (Thailand, Jepang, Singapur, Saudi Arabia) tidak jauh berbeda. Siswa yang memiliki postur tubuh di bawah rata-rata akan mengalami kesulitan tatkala mengerjakan dengan lokasi pekerjaan jangkauan yang jauh. Siswa yang memiliki postur tubuh di atas rata-rata pada dasarnya bukan mengalami kesulitan hanya dia akan bekerja dengan posisi yang cukup berat manakala menghadapi kendaraan yang lebih rendah dari posisi kerja idealnya.

Pada engine tune up salah satu pekerjaan pada service engine pekerjaan yang dilakukan adalah pekerjaan di bawah dada. Siswa yang mempunyai postur tubuh yang tinggi bekerja dalam kondisi membungkuk. Rata kerja dalam kondisi membungkuk maka punggung cenderung akan mengalami kelelahan yang lebih cepat sehingga kemungkinan besar akan terjadi rasa sakit pada punggung, pinggang dan leher/pundak. Bagi yang mempunyai postur tubuh dibawah rata-rata akan mengalami kelelahan dan rasa sakit pada bagian perut dan dada bagian bawah. Penyebab kelelahan dan rasa sakit timbul ketika berusaha menjangkau bagian/komponen yang jauh dari bagian perut dan dada menyentuh fender dan grill kendaraan (White \& Fedyani, 2011). Bagi kelompok siswa yang berada dibawah atau diatas rata-rata bisa diatasi dengan penambahan atau penggunaan alat bantu sehingga siswa tidak akan 
mengalami kesulitan ketika melakukan pekerjaan. Sebagai contoh alat bantu tersebut adalah car lift.

\section{KESIMPULAN}

Hasil pengukuran anthropometri kondisi ketubuhan (postur tubuh) calon mekanik otomotif pada pemetaan tingkat keseragamannya relatif rendah. Perbedaan data yang tinggi dan rendah apabila dilihat secara keseluruhan dari rata-rata siswa mempunyai tinggi badan rata-rata $165,30 \mathrm{~cm}$ dan berat badan rata-rata 56,68 $\mathrm{kg}$. Postur tersebut menunjukkan bahwa calon mekanik otomotif tersebut memenuhi syarat untuk menjadi mekanik otomotif di Indonesia. Adapun keseragaman data anthropometri postur tubuh siswa calon mekanik yang relatif kecil menyebabkan pemetaan pola pembelajaran khusus. Pola pembelajaran khusus dimana postur tubuh yang rendah dan tinggi pada saat praktik diberikan alat bantu kerja.

\section{DAFTAR PUSTAKA}

Gupta, D. \& Zakaria, N. (2014). Anthropometry, Apparel Sizing and design. Cambridge: Woodhead.

Knudson, D. (2007). Fundamentals of Biomechanic. New York: Springer.

Kroemer, K. H. E. et. al. (2010). Engineering Phisiology. Heidelberg: Springer.

Kuswana, S. W. (2013). Dasar-Dasar Pendidikan Vokasi dan Kejuruan. Bandung: Alfabeta.

Kuswana, S. W. (2014). Ergonomi dan K3 (Kesehatan, Keselamatan Kerja). Bandung: Remaja Rosdakarya.

Kuswana, S. W. (2015). Antropologi Terapan untuk Perancangan Sistem Kerja. Bandung: Remaja Rosdakarya.

Preedy, R. V. (2012). Handbook of Anthropometry Physical Measures of Human Form in Health and Disease. New York: Springer.

White, K . A, \& Fedyani. (2011). Pengantar Sosiologi Kesehatan dan Penyakit. Jakarta: Rajagrafindo Persada.

Wignjosoebroto, S (2003). Ergonomi Studi Gerak dan Waktu. Surabaya: Guna Widya. 